Published in final edited form as:

Harv Rev Psychiatry. 2009 ; 17(2): 87-102. doi:10.1080/10673220902891877.

\title{
Reproductive Aging, Sex Steroids, and Mood Disorders
}

\author{
Veronica Harsh, MD, \\ National Institute of Mental Health, Section on Behavioral Endocrinology \\ Samantha Meltzer-Brody, MD, MPH, \\ University of North Carolina at Chapel Hill-Psychiatry \\ David R. Rubinow, MD, and \\ University of North Carolina at Chapel Hill—Psychiatry \\ Peter J. Schmidt, MD \\ National Institute of Mental Health, Section on Behavioral Endocrinology
}

\begin{abstract}
Epidemiologic studies have documented that the majority of women do not become depressed during the menopause transition. However, recent longitudinal studies suggest that in some women, the events related to the menopause transition could play a role in the onset of depression. In this article we review evidence suggesting a relationship between the menopause transition and depression. Additionally, we describe several findings that suggest a role of ovarian hormones in the onset of these depressions, including the clustering of episodes of depression during the stage of the menopause transition that is accompanied by estradiol withdrawal, and the therapeutic effects of short-term estradiol in depressed perimenopausal women. Finally, we discuss possible causes of affective disturbances during the menopause transition.
\end{abstract}

\section{Keywords}

depression; estrogen; menopause transition

\begin{abstract}
The focus of this article is the potential relationship between the onset of affective disorders in women and the reproductive events of the menopause transition. First, we will present background information relevant to the controversy surrounding the putative relationship between reproductive aging and affective disorders, review the endocrinology of this phase of a woman's life, and describe those methodologic problems that have hindered efforts to clarify the existence and nature of a potential relationship between the onset of depression and the menopause transition. Second, we will describe studies examining the prevalence and presentation of mood disorders occurring during the menopause transition. We will also emphasize several emerging methodologic issues that may help resolve otherwise discrepant findings between previous epidemiologic studies and those published more recently. Third, we will review evidence from basic studies that both demonstrate the manifold regulatory actions of ovarian steroids on central nervous system (CNS) function and provide biologically
\end{abstract}

(C) 2009 President and Fellows of Harvard College

Correspondence: Peter J. Schmidt, MD, NIMH—Section on Behavioral Endocrinology, 10 Center Dr., MSC 1276, Bethesda, MD 20892-1276. PeterSchmidt@mail.nih.gov.

Declaration of interest: Dr. Meltzer-Brody receives research support from AstraZeneca and the Foundation of Hope, and in the past has received funding from Glaxo-SmithKline. Drs. Rubinow and Schmidt have received material support (estrogen and placebo skin patches) from Watson Pharmaceuticals. 
plausible mechanisms that could underly the relationship between the reproductive events during the menopause transition and the onset of affective disorders. Finally, we will discuss possible causes of affective dysregulation during the menopause transition.

\section{HISTORICAL PERSPECTIVES}

The nineteenth-century medical literature contains numerous case reports and medical commentaries describing mood and behavioral disorders in women during midlife and reproductive aging. In his 1899 Textbook of Mental Disease, Bevan Lewis ${ }^{1}$ described the clinical presentations of women with climacteric-related mood disorders as follows:

Pre-eminently is this the case at the menopause and grand climacteric, when the whole of this system loses its functional activity, degenerates, and, in fact, passes almost completely out of the life of the individual. Both subjective and objective accompaniments of the menstrual molimen in a greatly-exaggerated degree emphasise and usher-in this serious disturbance of the nervous-centres-headache, vertigo, faintness, "heat flushes," emotional waves, phases of moral perversity, irritability, querulous impatience, even intellectual disturbance (especially of memory and of attention) prevail; and, wanting the relief afforded by the depurative process of menstruation, the distress is often a long-continued and urgent one. This, however, is the earlier stage of functional decrepitude, the early phase of which is characterised by want of decision, lassitude, and hebetude. It is essentially a period of voluminous emotions, purposeless waves of feeling, abortive yearnings, redundant, vague, uncontrolled desires, and misdirected energy. That great reservoir of nerve-force, which had for its object the procreative functions of the organism, is now objectiveless, and its expenditure must now be directed into other channels; a period of emotional instability ushers in a period of reconstructions.

These early observations, in turn, led to speculations about the role of ovarian steroids in brain function and psychiatric illness, speculations supported by the anecdotal reports of the psychotropic actions of ovarian extracts. Nonetheless, in the psychiatric literature, a debate ensued regarding the nature of these mood and behavioral disturbances and their connection to reproductive aging. Descriptions of involutional- and climacteric-related syndromes in the nineteenth century ranged from minor depressive illnesses (neurasthenia-like) to more severe forms of depressive illness with psychotic features. For example, Conklin ${ }^{2}$ described a syndrome reminiscent of minor depression or a mixed anxiety-depressive state occurring in the context of vasomotor symptoms and numerous somatic symptoms, whereas Maudsley ${ }^{3}$ reported a more classical endogenomorphic depression, in association with delusions of guilt and episodes of psychomotor agitation. The depression described by Maudsley in England was also described in Germany by both Kraepelin ${ }^{4}$ and Bleuler. ${ }^{5}$ Although Kraepelin's description of involutional melancholia was not confined to women, the described clinical presentation resembled Maudsley's climacteric melancholia. Based on the clinical presentations (e.g., late onset, absence of mania), involutional melancholia was excluded from manic-depressive psychosis and considered a separate entity with a variable prognosis. The separateness of this syndrome was postulated on the basis of differences in symptomatology, age of onset of index episode, premorbid personality, and family history. Subsequently, Stenstedt ${ }^{6}$ further distinguished menopause-related involutional patients from other types of involutional depression by observing the former group to exhibit less severe symptoms and lower risk for affective disorder in family members. The controversy surrounding these conditions was not whether a menopausal mood syndrome existed, but how it should be classified.

Despite the debate over classification, a mood disorder called involutional psychotic reaction appeared in the first Diagnostic and Statistical Manual of Mental Disorders (DSM). ${ }^{7}$ The association between involutional depression and ovarian aging was supported further following 
the successful isolation and synthesis of ovarian steroids. The widespread use of estrogen therapy in the 1940s led to reports of the therapeutic benefits of estrogen therapy in women with involutional melancholia. ${ }^{8}$ Thus, mainstream psychiatry (albeit not without dissent) ${ }^{9}$ accepted the existence of a type of mood disorder related to reproductive aging—and, in fact, inferred a causal association between the two events, given both the timing of onset and preliminary suggestions of the beneficial effects of estrogen therapy.

Prior to DSM-III, several more systematic studies investigated the nature of the relationship between the reproductive aging and the onset of mood disorders in women. In particular, studies by Weissman ${ }^{10}$ and Winokur ${ }^{11}$ were unable to confirm the existence of involutional melancholia or to identify epidemiologic evidence for an increased prevalence of major depressive disorder during the menopause. Thus, the earlier debate over the appropriate classification of involutional melancholia changed to skepticism about its existence as a distinct condition. Moreover, these findings suggested that hormonal events did not underlie mood disorders occurring during midlife and reproductive aging.

In summary, several studies ${ }^{10-12}$ provided evidence against the validity of the involutional melancholia construct in that (1) there appeared to be no distinct symptom pattern, (2) there was no distinct pattern of previous episodes of depression in patients with menopause-related major depressive episodes, (3) there was no increased risk for suicide or psychiatric hospitalization during the menopause, and (4) there appeared to be no increased prevalence of depression during the menopause. Additionally, despite a generally higher prevalence rate of depression in females compared to males, some studies ${ }^{12}$ reported a slightly lower six-month prevalence rate of depression during the presumed menopausal/climacteric years than in younger age groups.

This evidence, however, was far from conclusive in refuting the existence of a menopauserelated mood syndrome. Despite similar or lower point prevalence rates and similar clinical presentations of depression during the menopause and at other times of life, one cannot infer that these syndromes share identical etiologies. For example, both Stenstedt ${ }^{6}$ and Brown and colleagues ${ }^{13}$ reported involutional-onset depression to be associated with a lower family history of depression than that observed in patients with early-onset depression. Thus, although major depressions that occur during the menopause do not appear phenomenologically distinct from earlier-onset depressions, evidence suggests that the two may differ with respect to family history and the age of the index depressive episode.

The presupposition that menopause-related affective syndromes, if they exist, are forms of melancholic depression is an additional confound that may have interfered with the identification and characterization of other affective syndromes (e.g., minor depression) occurring at or around the menopause. Many of the original reports described a clinical picture during the menopause that was more consistent with a neurasthenia or minor depression. For example, Winokur ${ }^{11}$ observed that the symptoms of depression and anxiety were so common during the menopause that an additional criterion for depression (i.e., hospitalization) was imposed for the older (but not the younger) depressed women, thus spuriously decreasing the rate of observed affective disorders in the years surrounding the menopause. Given Winokur's observation of the high frequency of reports of menopause-related affective symptomatology in this group, it seems unwarranted for him to have concluded that there is "little value in looking specifically at the menopausal state for clues to the etiology of ordinary affective disorder." 


\section{REPRODUCTIVE ENDOCRINOLOGY OF THE MENOPAUSE TRANSITION AND THE POSTMENOPAUSE}

The menopause is defined as the permanent cessation of menstruation resulting from loss of ovarian activity. It is characterized endocrinologically by tonically elevated gonadotropin (follicle stimulating hormone [FSH], luteinizing hormone [LH]) secretion, persistently low levels of ovarian steroids (estradiol, progesterone), and relatively low (50\% decrease compared to younger age groups) androgen secretion. ${ }^{14}$ The menopause transition and perimenopause are defined as the transitional periods from reproductive to nonreproductive life. ${ }^{15}$ The average duration of the menopause transition (defined by menstrual cycle irregularity) is estimated to be approximately 4 years, but there is considerable individual variation in the duration of this phase of reproductive life, ranging from 0 to 11 years. ${ }^{16,17}$ During the early stages of reproductive aging, the follicular phase of the menstrual cycle shortens, ${ }^{18,19}$ early follicular phase plasma FSH levels increase, and plasma inhibin B levels decrease. ${ }^{20-22}$ As the menopause transition progresses, ovarian follicular depletion occurs, the ovary becomes less sensitive to gonadotropin stimulation, and a state of relative hypoestrogenism occurs; gonadotropin secretion is elevated across the menstrual cycle; ovulatory cycles are fewer; and menstrual cycle irregularity ensues. In contrast to the postmenopause, however, episodic (not tonic) gonadotropin secretion is present, and both ovulation and normal premenopausal (or at times, increased) estradiol secretion may occur. ${ }^{15,23-25}$ The late menopause transition is characterized endocrinologically by persistent elevations of plasma FSH, sustained menstrual cycle irregularity with periods of amenorrhea, and hypoestrogenism. Also decreasing with aging, concomitant with changes in reproductive function, are the levels of several other hormones that may affect mood and behavior-including androgens (testosterone and androstenedione), which begin to decline in the $20 \mathrm{~s}$ and reach peak decline during the late $40 \mathrm{~s}$ and 50s, dehydroepiandrosterone (DHEA), and insulin-like growth factors and binding proteins. ${ }^{23,26-29}$

Not only is there evidence suggesting the importance of distinguishing between peri- and postmenopausal women with respect to treatment response characteristics (see below), but studies also have identified that the perimenopause has distinct endocrine characteristics, with the early menopause transition (e.g., high gonadotropin levels and possibly increased estradiol secretion) differing from the late menopause transition (e.g., high gonadotropin levels, estradiol withdrawal, and initial onset of sustained hypogonadism). Thus, investigators have attempted to develop criteria to define the phases of reproductive aging more carefully and thereby to facilitate a more precise understanding of the interaction between the stage of ovarian failure, aging, and a variety of physiological events. For example, the Stages of Reproductive Aging Workshop (STRAW) criteria for reproductive, perimenopausal (menopausal transition), and postmenopausal years developed by Soules and colleagues ${ }^{14}$ define the early menopause transition (stage -2) to include women with menstrual cycle irregularity (defined as a variable cycle length that differs from normal by more than 7 days) and elevated plasma FSH secretion, whereas during the late menopause transition (stage -1), there is a continued elevation of FSH in conjunction with two or more skipped cycles and a period of amenorrhea lasting at least 60 days. The perimenopause includes both stages -2 and -1 , as well as up to one year of amenorrhea after which the woman has entered the early postmenopause.

\section{PAST METHODOLOGIC PROBLEMS AND EMERGING CONCEPTS IN INVESTIGATIONS OF THE RELATIONSHIP BETWEEN MOOD DISORDERS AND REPRODUCTIVE AGING}

Methodologic problems in previous studies related to the manner in which both reproductive status and mood syndromes were defined have compromised researchers' ability to understand 
the role of reproductive aging in mood disorders and the role of estradiol in treating these disorders.

\section{Characterizing Reproductive Status}

Several criteria have been employed to define the reproductive status of women participating in studies of the relationship between menopause and mood. One criterion is to use an age window of 45 to 55 years to select perimenopausal subjects. Although the average age of the menopause is 51 years, there is considerable individual variation in the age of onset of the menopause, ranging from the early 40s to the late 50s. Adopting an age window as the sole selection criteria will inevitably result in the selection of a heterogenous sample of women, with some premenopausal, some perimenopausal, and some postmenopausal. Under a second criterion, age is combined with retrospective or prospective self-reports of menstrual cycle disturbance; the menopause is defined as six months to one year of amenorrhea, and the perimenopause as menstrual cycle irregularity. Self-reports of menstrual cycle irregularity, however, cannot be used to reliably define reproductive status. Treloar ${ }^{16}$ observed that menstrual cycle irregularity is not confined to the perimenopause and may occur frequently during other periods of reproductive life. In a sample of women at midlife, Kaufert and colleagues $^{30}$ observed that during a three-year period of follow-up, as many women reporting menstrual cycle irregularity returned to normal menstrual cycle function as entered the menopause (defined by six months of amenorrhea). Moreover, there is a 5\%-10\% probability that a woman could have menstrual bleeding even after 12 months of amenorrhea. ${ }^{31}$ Finally, recent studies suggest that either persistent cycle lengths of $>40$ days or periods of amenorrhea of $>60$ days are more predictive of the onset of the menopause within one to two years than the less specific criteria of either isolated episodes of elongated cycles or skipped menses. ${ }^{32}$, 33 Thus, previous studies relying on self-reports of menstrual cycle irregularity also would be at risk for selecting samples of women at different stages of reproductive aging. A third criterion commonly used to define reproductive status is the presence of elevated plasma FSH levels. Perimenopause-related elevations in gonadotropins may be reversible, however, and in our sample of 310 women who had four serial FSH levels drawn every two weeks for six weeks, an elevated FSH (>20 IU/L) during the first sampling was not subsequently confirmed in $10 \%$ of cases (Khine et al., unpublished data). Indeed, a recent study confirmed that an elevated plasma FSH level is an independent marker of the late menopause transition; however, FSH levels alone were less predictive of menopausal stage than bleeding patterns. ${ }^{34} \mathrm{~A}$ combination of age, menstrual cycle history, and plasma gonadotropin levels may be the most reliable method for selecting and characterizing the reproductive status of perimenopausal women, but it will not be predictive of future reproductive function in every woman.

\section{Defining Mood Syndromes}

Another methodological problem is the failure to define midlife mood disorder as a syndrome - as a condition meeting standardized diagnostic criteria; what is seen, instead, is only an unintegrated set of symptoms. Mood symptoms differ from mood syndromes, however, in their instruments of detection, their duration, and their impact. Structured interviews introduce criteria similar to those present in DSM-IV ${ }^{35}$ to ensure diagnostic homogeneity within samples and comparability across studies. For example, in addition to the presence of the DSM-IV core symptom criteria, the Structured Clinical Interview for DSM-IV (SCID-IV) ${ }^{36}$ specifies that symptoms of depression must be present nearly every day for most of the day and persist for at least two weeks. The SCID also requires that the severity of depression be rated from mild to severe based on the number of symptoms in excess of those required for the diagnosis of minor or major depression and the level of functional impairment. In contrast, the crosssectional scales employed in many community-based surveys measure the severity of depressive-like symptoms but do not assess either the longitudinal persistence of a core group of depressive symptoms or the level of functional impairment, both important constituents of 
a depressive syndrome. Additionally, cross-sectional rating scales, such as the Center for Epidemiological Studies-Depression (CES-D), have restricted sampling intervals consisting of a one- to two-week window of time prior to the date when the scale is completed. Thus, if $50 \%$ of major depressive episodes remit within three months, as reported previously, ${ }^{37}$ then the administration of a cross-sectional rating on a yearly basis, for example, could not reliably assess the occurrence of depression during the previous year. ${ }^{38}$

In addition employing standardized psychiatric diagnostic interviews to establish the presence of current and past psychiatric mood syndromes, investigators need to define and identify the type of mood syndromes that they are investigating. For example, both major and minor depressions exist, yet many studies focus only on the presence of major depression, with the exclusion of minor depression justified on the basis of its lesser significance. During the puerperium, however, the incidence of minor depression is comparable to that of major depression. ${ }^{39}$

\section{MOOD DISORDERS OCCURRING DURING REPRODUCTIVE AGING IN WOMEN}

The majority of women do not develop depression during the menopause transition or after the menopause. In fact, epidemiologic studies examining gender- and age-related differences in the six-month to one-year prevalence of major depression reported no increased prevalence of major depression in women at midlife (age range approximately $45-55$ years). ${ }^{40,41}$ Similarly, others have concluded that the onset of the menopause is not associated with an increased risk for developing depression; ${ }^{42-51}$ however, in four studies, ${ }^{44,45,49,50}$ symptoms were observed more frequently in perimenopausal than postmenopausal women. Indeed, in several other longitudinal, community-based studies, the perimenopause (or the presence of menstrual cycle irregularity and hot flushes) was associated with an increased risk for depression, ${ }^{52-57}$ consistent with studies of women attending gynecology clinics. ${ }^{58-60}$ The Study of Women's Health Across the Nation (SWAN) ${ }^{54}$ employed a measure of "psychological distress" as a proxy for the syndrome of depression by requiring that core depressive symptoms (sadness, anxiety, and irritability) persist for at least two weeks (similar to the duration criterion employed in DSM-IV). SWAN's initial cross-sectional survey observed that perimenopausal women reported significantly more "psychological distress" than either pre- or postmenopausal women (defined by self-reported menstrual cycle status). ${ }^{54}$ The results of several studies published during the last three years have found similar results. First, in a longitudinal study, Freeman and colleagues ${ }^{57}$ found an increased risk for clinically significant depression (defined by elevated CES-D scale scores and the Primary Care Evaluation of Mental Disorders) ${ }^{61}$ during the perimenopause compared to the pre- or postmenopause. This association remained after adjusting for several variables, including past history of depression, severe premenstrual syndrome, poor sleep, and hot flushes. Levels of depression were increased relative to those found in postmenopausal women; however, only $3 \%$ of the sample (approximately ten of the women in the study) was followed through to the postmenopause. In a second prospective study, Cohen and colleagues ${ }^{62}$ evaluated the risk of depression in 460 women who were followed prospectively for up to seven years and who had no past history of depression. The risk of new-onset depression (defined by the SCID-IV) in the perimenopause was nearly twice that observed in the premenopause (adjusted OR $=1.8$ ). Third, in a similar study to that of Cohen and colleagues, ${ }^{62}$ Freeman and colleagues ${ }^{63}$ demonstrated a significantly increased ( $2 \frac{1}{2}$ times greater) rate of new-onset depression in women with no history of depression during the late perimenopause compared to women with no history of depression who remained premenopausal. Finally, two recent reports by Bromberger and colleagues ${ }^{64,65}$ demonstrate an increased incidence of first-onset and recurrent major and minor depressive episodes during the late menopause transition and early postmenopause. These data notwithstanding, the majority of women in these studies remained asymptomatic throughout the perimenopause. 
These data suggest, however, that events occurring during the menopause transition and early postmenopause may predispose some women to develop clinically significant depressive illness.

The stage of the menopause transition during which episodes of depression appear could provide clues to the physiologic events accompanying the onset of depression. We have examined the temporal linkage between the stages of the menopause transition and depression in two studies. First, we prospectively examined asymptomatic premenopausal women with regular menstrual cycles to determine if the onsets of depression clustered during a specific stage of the menopause transition. Women were followed with behavioral and reproductive measures for an average of five years until six months to one year after the last menstrual period. In a preliminary report of 29 women, we documented nine episodes of major or minor depression in 8 women, only 2 of whom had a prior depressive episode. A 14-fold increase in the rate of onset of depression was observed during the 24 months surrounding the final menstrual period, relative to the 31 years used as a comparison time period. These data document a clustering of depressive episodes in women during the late menopause transition relative to the premenopause. ${ }^{66}$ Second, we performed a cross-sectional study of 116 women presenting to the National Institute of Mental Health midlife clinic for evaluation and treatment -all of whom met criteria for perimenopause-onset major or minor depression. The majority of depressive episodes occurred during STRAW stage 1 (the late menopause transition), regardless of the presence of vasomotor symptoms or a past history of depression. ${ }^{67}$ The stage of the menopause transition (i.e., late stage) during which depressive episodes appear supports a pathophysiologic role of endocrine events since the late perimenopause is characterized by estradiol "withdrawal" relative to either the postmenopause or the early perimenopause. ${ }^{15,23}$ Thus, the temporal appearance of the depressions observed suggests an endocrine trigger related to the perimenopause (estradiol withdrawal or recent onset of prolonged hypogonadism) in the onset of perimenopausal depression.

\section{Anxiety Symptoms and Syndromes}

There also is evidence that clinically significant symptoms of anxiety are experienced by a considerable number of women during the menopause transition ${ }^{60}$ and that the frequency of episodes may increase during the perimenopause. ${ }^{68-71}$ Freeman and colleagues ${ }^{71}$ measured anxiety symptoms with the Zung Inventory in a group of women followed prospectively through the menopause transition until the final menstrual period. Significant associations between the severity of anxiety symptoms and the occurrence, severity, and frequency of hot flushes were identified in these women. Women with the highest anxiety scores (i.e., Zung Inventory scores $>48$ ) were five times more likely to report hot flushes compared to the nonanxious perimenopausal women. An increase in the severity of anxiety symptoms during the menopause transition predicted the occurrence of hot flushes 8 to 12 months later. These significant associations remained after adjusting for smoking, body mass index (BMI), race, and depressive symptoms. Thus, the increased autonomic activity and arousal associated with anxiety could increase a woman's vulnerability for experiencing hot flushes or could exaggerate their distressing symptoms. Alternatively, the symptoms of anxiety disorders and of hot flushes may overlap such that scores on an anxiety measure may be increased in women who have hot flushes. These data also emphasize that in addition to mood disorders, anxiety could play a prominent role in the psychological and somatic distress experienced by some perimenopausal women.

Anxiety syndromes may also occur during the menopause transition. New-onset panic disorder in the perimenopause was observed anecdotally (Schmidt et al., unpublished observation) and may be responsive to estrogen therapy; in our experience, however, the frequent comorbidity of perimenopausal panic disorder with hot flushes and their shared symptomatology prevent 
one from readily separating the two phenomena. Thus, although estradiol treatment may be effective for panic attacks, it is unclear if this improvement is secondary to relief of hot flushes (which may trigger as well as mimic panic attacks) or due to the direct effects of estradiol on panic disorder. Moreover, both hot flushes and panic improve after treatment with selective serotonin reuptake inhibitors, suggesting potentially shared pathophysiology and also treatment response characteristics.

\section{Emerging Concepts}

These recent studies ${ }^{56,57,62-67}$ of the relationship between reproductive aging and mood disturbance have employed more reliable methods for both establishing the presence or absence of mood syndromes (e.g., structured diagnostic interviews) and characterizing reproductive status (e.g., STRAW criteria). ${ }^{14}$ Thus, several new methodologic issues have been identified that may predict a differential response to changes in hormones (either endogenous or exogenous), including phase of reproductive aging (i.e., late perimenopause or early menopause versus five years past last menses), presence of menopausal symptoms, the duration of hypogonadism prior to receiving hormone therapy, and genetic polymorphisms that underlie differences in steroid responsivity. A differential response to estradiol in depression was reported by Appleby, ${ }^{72}$ with perimenopausal, but not postmenopausal, women responding to estrogen therapy under randomized, placebo controlled conditions (observations confirmed by several recent randomized, controlled trials [described below] employing standardized psychiatric diagnostic interviews to establish the presence of depression) ${ }^{73-75}$ Similarly, a

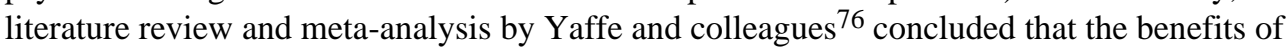
hormone therapy on cognitive function were limited to perimenopausal women compared to postmenopausal women and suggested that the beneficial effects of hormone therapy were secondary to the concurrent improvement in menopausal symptoms. Subsequent metaanalyses of a similar literature performed by LeBlanc ${ }^{77}$ and Hogervorst ${ }^{78}$ confirmed Yaffe's $^{2}$ suggestion and observed that the presence of symptoms (e.g., hot flushes, sleep disturbance, or mood disturbance) predicted a beneficial effect of hormone therapy on cognition. Similarly, studies in both animals and humans suggest that a short duration of hypogonadism prior to initiation of estrogen therapy is associated with beneficial effects on measures of cognition ${ }^{79-81}$ and on atherosclerotic plaque formation. ${ }^{82}$ These findings are consistent with the observed differences in treatment response between perimenopausal or recently menopausal and older postmenopausal women - the former being more likely to be symptomatic. ${ }^{58,59}$ Additionally, these findings introduce the concept of the critical window for the efficacy of estrogen therapy. For example, both non-human primate and, more recently, human studies have shown that initiation of hormone is associated with cardioprotection when administered immediately after oophorectomy — but not after 30 months (approximately six human years) in nonhuman primates or during the early postmenopause in women. ${ }^{82-86}$ This critical-window construct was proposed as an explanation for some of the discrepant findings between the observational studies (many of which included younger, more symptomatic women) and the recent randomized, controlled trials related to the Women's Health Initiative, 87,88 which principally included older asymptomatic women. ${ }^{81,89}$ Finally, independent of stage of reproductive life or duration of hypogonadism, several studies employing both plasma lipid levels and cognitive-outcome measures suggest that the effects of sex steroids may be influenced by the presence of polymorphisms in specific steroid receptors. ${ }^{90,91}$

In summary, epidemiologic studies examining the prevalence of both affective symptoms and syndromes have documented that the majority of postmenopausal women do not experience a major depression associated with this phase of life. Nevertheless, several community-based and clinic-based surveys suggest that the perimenopause is relevant to the development of affective disorders and that a substantial number of perimenopausal women do, in fact, experience a clinically significant affective syndrome. 


\section{NEUROREGULATORY POTENTIAL OF ALTERATIONS IN OVARIAN STEROID SECRETION}

Results from animal and human studies demonstrate that gonadal steroids influence several of the neuroregulatory systems thought to be involved in both the pathophysiology of affective disorders and the efficacy of antidepressant therapies. ${ }^{92-94}$ These findings suggest that under certain circumstances the changes in ovarian steroids accompanying the menopause transition could sufficiently alter brain function so as to manifest in affective maladaptation and depression. Preclinical, pharmacological, postmortem, and in vivo imaging studies implicate alterations in classical neurotransmission (e.g., increased serotonin transporter function; decreased cortical 5HT1A receptors) in the etiology and treatment of depression. In some, but not all, ${ }^{95}$ experimental paradigms, estradiol, like antidepressants, has been observed to inhibit serotonin transporter mRNA, protein, and binding; $; 6-98$ decrease $5 \mathrm{HT} 1 \mathrm{~A}$ receptor activity (down-regulation and uncoupling from its G-protein); 99,100 increase 5HT2A binding and mRNA; ${ }^{101}$ and facilitate imipramine-induced downregulation of 5HT2 receptors in rat frontal cortex. ${ }^{102}$

In addition to classic neurotransmitter systems, several neural-signaling systems have been identified as potential mediators of the therapeutic actions of antidepressants and electroconvulsive therapy (ECT) (e.g., cyclic adenosine monophosphate [cAMP] response element-binding protein [CREB] and brain-derived neurotrophic factor [BDNF] ${ }^{103}$ based on observations that these systems are modulated by a range of therapies effective in depression (e.g., serotonergic and noradrenergic agents and ECT) and that they exhibit patterns of change consistent with the latency to therapeutic efficacy for most antidepressants. ${ }^{104}$ For example, antidepressants increase the expression and activity of CREB in certain brain regions (e.g., hippocampus) ${ }^{105}$ and regulate (in a brain region-specific manner) activity of genes with a cAMP response element. ${ }^{104}$ Genes for BDNF and its receptor TrkB have been proposed as potential targets for antidepressant-related changes in CREB activity, ${ }^{104-106}$ and recent reports demonstrate that BDNF levels are increased by treatment with antidepressants ${ }^{107-109}$

Similarly, estradiol was reported to influence many of these same neuroregulatory processes. Specifically, in animal models, ovariectomy was reported to decrease, and estradiol increase, BDNF levels in the forebrain and hippocampus. ${ }^{110-112}$ In the rat brain, estradiol also increases CREB activity ${ }^{113}$ and TrkA, ${ }^{110}$ and decreases GSK-3 beta activity (Wnt pathway) in a direction similar to that seen with mood stabilizers. In contrast, an estradiol-induced decrease in BDNF was reported to mediate estradiol's regulation of dendritic spine formation in hippocampal neurons. ${ }^{114}$ Polymorphisms in genes involved in signal transduction may also influence the response to treatment. ${ }^{115}$ For example, polymorphisms in the G-protein beta subunit GNB3 C825T, which results in a 41 amino acid deletion, have been significantly associated with lack of remission and response to antidepressant treatment. ${ }^{116}$ Data from animal and human studies demonstrate the ability of estradiol to regulate G-protein function. ${ }^{117-119}$ Finally, through effects on cell-survival proteins (e.g., Bcl-2, BAX) and proliferative signal transduction pathways (MAPK, Wnt, Akt), both reproductive steroids and antidepressants/mood stabilizers may influence cell energetics in such a way as to influence synaptic plasticity, a process that is putatively disturbed in depression. Thus, the therapeutic potential of gonadal steroids in depression is suggested not only by their widespread actions on classical neurotransmitter systems, but also by a variety of other relevant neuroregulatory actions shared by both estrogen and traditional therapies for depression (i.e., antidepressants, mood stabilizers, ECT). 


\section{POSSIBLE CAUSES OF MOOD DISORDERS DURING REPRODUCTIVE AGING}

\section{Ovarian Hormone Withdrawal or Deficiency Theory}

Several reports indirectly support a role for abnormalities of reproductive hormones during the perimenopause in depression: (1) hormone replacement beneficially affects both hot flushes and mood in hypogonadal women; ${ }^{120-123}$ (2) lower gonadotropin levels are sometimes observed in postmenopausal, depressed women compared to asymptomatic comparison groups, ${ }^{124-127}$ (3) perimenopausal women with depressive symptoms are reported to have lower plasma estrone levels ${ }^{128}$ than nondepressed, perimenopausal women; and (4) an association has been described between increased plasma FSH levels and depression. ${ }^{129}$ In contrast, three studies of perimenopausal and postmenopausal women observed either no diagnosis-related differences in plasma estradiol and $\mathrm{FSH}^{130}$ or no correlation between plasma levels of estrogens or androgens and severity of depressive symptoms. ${ }^{131,132}$

In a study of 21 women with their first episode of depression occurring during the perimenopause and 21 asymptomatic, perimenopausal controls, ${ }^{133}$ we were unable to confirm previous reports of lower basal plasma levels of $\mathrm{LH}^{124-127}$ or estrone ${ }^{128}$ in perimenopausal and postmenopausal women with depression. Additionally, no diagnosis-related differences in basal plasma levels of FSH, estrone, testosterone, or free testosterone were observed. These data are consistent with those of Barrett-Connor and colleagues ${ }^{131}$ and Cawood and colleagues, 132 who, as described above, found no correlation between mood symptoms and plasma levels of these hormones.

In addition to ovarian hormones, age-related differences in the function of several other physiologic systems are observed in both animals and humans. Some of these differences may occur coincident with the perimenopause and therefore may potentially contribute to mood dysregulation at this time. Although postmenopausal women are reported to exhibit increased stress-induced plasma norepinephrine levels compared to premenopausal women, ${ }^{134}$ only one previous study ${ }^{128}$ reported elevated urinary cortisol levels in perimenopausal women reporting depressive symptoms compared to asymptomatic controls. No systematic study has been performed of HPA-axis function in untreated perimenopausal depressed women.

A role for the adrenal androgen DHEA and its sulfated metabolite (DHEA-S) in the regulation of mood state is suggested by both its effects on neural physiology 135,136 and its potential synthesis within the central nervous system. ${ }^{137}$ Moreover, in clinical trials, DHEA administration was reported to improve mood in some, ${ }^{138-141}$ but not all, ${ }^{142}$ studies. DHEA's potential role in the onset of depression may be particularly relevant at midlife in view of the declining levels of DHEA production that occur with aging and the accelerated decrease in DHEA levels reported in women, but not men, during midlife. ${ }^{143}$ It is therefore possible that declining secretion (or abnormally low secretion) of DHEA may interact with perimenopauserelated changes in ovarian function to trigger the onset of depression in some women. We ${ }^{133}$ measured morning plasma levels of DHEA, DHEA-S, and cortisol in a sample of women with the first onset of depression during the perimenopause and in nondepressed women matched for age and reproductive status. Depressed perimenopausal women had significantly lower levels of both plasma DHEA and DHEA-S, but not cortisol, compared to controls. ${ }^{133}$ These findings are consistent with several previous studies suggesting an association between DHEA levels and mood. In one study, plasma DHEA levels correlated with the severity of depressive symptoms in a group of postmenopausal women, with lower levels of DHEA associated with higher depression scores. ${ }^{131}$ In two other studies, a positive correlation between DHEA-S plasma levels and feelings of well-being was observed in groups of peri- and postmenopausal women; ${ }^{132}$ as well as in elderly depressed men and women. ${ }^{144}$ These differences in DHEA 
levels notwithstanding, there was considerable overlap in plasma DHEA levels between perimenopausal women with and without depression. Thus, at present, in addition to the limitations of basal hormonal measures, there is not consistent evidence that women who develop depression during the menopause transition have an ovarian or adrenal hormone deficiency state.

Perimenopausal depression may not be distinguished from major depressive disorder on the basis of phenomenology, course, family or personal history of mood disorder, or abnormal basal levels of ovarian/adrenal steroids. Nonetheless, the relevance of changes in pituitaryovarian function to depression during the perimenopause is suggested by two sets of findings: first, in some depressed, perimenopausal women, mood symptoms improve concurrently with the restoration of ovarian function; ${ }^{145}$ and second, estradiol therapy has mood-enhancing effects in depressed, perimenopausal women.

First, we observed several women who presented to our clinic with depression and whose plasma FSH levels, obtained at each clinic visit, declined over a 6-8 week period, concurrent with spontaneous improvements in mood symptoms. We examined whether this putative relationship between normalization of ovarian function and mood could be generalized. In particular, we evaluated mood scores and plasma FSH levels serially over a six-week screening phase in a larger group of women presenting to our clinic with perimenopausal depression. In the group of women $(n=18)$ whose CES-D scores decreased by $>50 \%$, we observed an incremental decline in FSH levels at each of the four clinic visits that paralleled the improvements in CES-D scores. ${ }^{145}$ Increased plasma FSH levels were not consistently associated with worsening CES-D scores, and increased CES-D scores were not associated with corresponding elevations in plasma FSH levels, whereas a more uniform relationship was observed between mood and plasma FSH level when either measure decreased. Thus, we identified a subgroup of women with perimenopausal depression whose mood symptoms remitted spontaneously in association with a significant decline in gonadotropin levels (and a suggested alteration in pituitary-ovarian function). While not fully convergent with our observations, in the longitudinal study by Freeman and colleagues, ${ }^{63}$ mood symptoms were significantly correlated with both declining plasma estradiol and increasing plasma FSH levels in those women who entered the late menopause transition and were at the increased risk for first-onset depression. In contrast to cross-sectional studies that suggest that perimenopausal depression is not associated with abnormalities of ovarian function, longitudinal studies imply that there may be a more direct relationship between alterations in pituitary-ovarian function and mood symptoms in these women.

In the second set of findings, an association between the endocrine events related to the perimenopause and the onset of depression is also implicated (albeit indirectly) by reports of the mood enhancing effects of estradiol in depressed, perimenopausal women. Recently, three double-blind, placebo-controlled trials, which used similar methodologies and identical preparations of estradiol (i.e., 17 beta estradiol), have examined the efficacy of estradiol in perimenopausal and postmenopausal women with major or minor depressions ${ }^{73-75}$ In the first of these studies, the therapeutic efficacy of estradiol (17 beta estradiol) was examined in a double-blind, placebo-controlled trial in 34 perimenopausal women (late perimenopause by STRAW criteria) ${ }^{14}$ who also met standardized diagnostic criteria for major and minor depression. ${ }^{73}$ After three weeks of estradiol, scores on depression-rating scales were significantly decreased compared to baseline scores and significantly lower than scores in the women receiving placebo. A full or partial therapeutic response was seen in $80 \%$ of subjects on estradiol and in $22 \%$ of those on placebo, which is consistent with the observed effect size of 0.7 in a meta-analysis of studies examining estrogen's effects on mood. ${ }^{146}$ The therapeutic response to estrogen was observed in women regardless of the presence of major or minor depression, a history of non-perimenopause-related depression, or the presence of hot flushes. 
Finally, neither baseline nor posttreatment estradiol levels predicted the observed therapeutic response. In keeping with recent community-based cross-sectional surveys,${ }^{54}$ these data suggest that estrogen's effect on depression is not solely a product of its ability to reduce the distress of hot flushes. These findings also are consistent with data from Montgomery and colleagues ${ }^{147}$ and Saletu and colleagues, ${ }^{148}$ which document the beneficial effects of estradiol on mood in perimenopausal women reporting depressive symptoms.

A second randomized, double-blind, placebo-controlled study by Soares and colleagues ${ }^{74}$ confirmed the observations of Schmidt and colleagues. ${ }^{73}$ In addition to finding a significant, beneficial effect of estradiol replacement compared to placebo in women with perimenopauserelated major depression (as defined by the Primary Care Evaluation of Mental Disorders), ${ }^{149}$ Soares and colleagues ${ }^{74}$ reported that baseline plasma estradiol levels did not predict response to estrogen treatment. In contrast, a recent study—one using a design similar to the ones employed by Schmidt, ${ }^{73}$ Soares, ${ }^{74}$ and their colleagues in studying perimenopausal women ${ }^{73,74}$-failed to observe a significant antidepressant effect of estradiol relative to placebo $^{75}$ in depressed women who were 5-10 years post menopause.

The evidence that younger perimenopausal, but not older postmenopausal, depressed women respond to estrogen therapy suggests that the mood disorders occurring in perimenopausal women are caused by changes in hormones (e.g., withdrawal or fluctuations) rather than by prolonged ovarian steroid deficiency.

\section{Hot Flushes and Dysphoria-The Cascade Theory}

A wealth of epidemiologic evidence demonstrates the co-occurrence of both hot flushes and depression in women during the perimenopause. ${ }^{42,52,57,134,150-152}$ In a randomized, controlled trial of 16 hypogonadal (peri- and postmenopausal) women, Schiff and colleagues ${ }^{153}$ showed that hot flushes, sleep, and mood all improved after treatment with oral conjugated estrogens. Based on these findings, a cascade-like effect was suggested in which hot flushes and perimenopausal depression share a linear, causal relationship between them (i.e., hot flushes lead to sleep disturbances, which, in turn, lead to dysphoria).

In support of the cascade theory, epidemiologic and clinic-based studies report an increased frequency of both hot flushes and sleep disorders in aging women during the menopause transition. Indeed, reports of insomnia have been documented in approximately $45 \%$ of perimenopausal women, with the highest rates of reported insomnia in women during the late menopause transition. ${ }^{74,154-157}$ Ohayon ${ }^{158}$ observed that over $80 \%$ of peri- and postmenopausal women with severe hot flushes also reported a sleep disturbance and that the severity of hot flushes correlated with the severity and duration of insomnia. Objective measurements of both sleep and hot flushes have confirmed these associations. Hot flushes recorded during the first half of the night are associated with frequent awakenings and subjective sleep disturbance, whereas hot flushes occurring during the second half of the night have less disruptive effects on sleep, possibly due to a buffering effect of REM sleep (e.g., the suppression of thermoregulation) on the sleep-disturbing effects of hot flushes. ${ }^{159}$ Nonetheless, in a separate study, awakening from sleep as frequently preceded a hot flush as it accompanied (or followed) one. ${ }^{160}$ Thus, these latter data do not support a specific linear, causal relationship between the occurrence of a hot flush and subsequent sleep disturbance. ${ }^{160}$ Epidemiologic data also confirm that disturbed sleep is a risk factor for the development of depression, ${ }^{161,162}$ and in one clinic-based study, healthy, nondepressed volunteers experienced depressive symptoms after two days of sleep deprivation. ${ }^{163}$ Thus, current evidence from both community- and clinic-based studies provides some, but not uniform, support for a direct, causal relationship between hot flush-induced sleep disturbances and depression in perimenopausal women. 
Despite the plausibility that hot flushes could sufficiently disturb sleep to result in an increased risk for depression in perimenopausal women, there is also evidence that challenges this putative association. First, sleep disturbance can be a symptom of, and not just a risk for, depression. Similarly, affective symptoms (e.g., anxiety) can precede hot flushes. ${ }^{71}$ Thus, the association of these phenomena does not demonstrate causation. Second, polysomnographic studies of peri- and postmenopausal women who complain of sleep disturbance have documented that over half of these women had sleep apnea or restless leg syndrome, neither of which is easily attributed to hot flushes. ${ }^{164}$ Third, for this relationship to be tenable, one would expect that reported hot flushes would occur prior to the onset of depression (i.e., as a precipitant of depression). Recent epidemiologic evidence suggests, however, that hot flushes and depression can also occur independently and are mutually dissociable phenomena. ${ }^{54,62}$, 63,165 Data from both the SWAN study ${ }^{54,165}$ and Freeman and colleagues ${ }^{57}$ demonstrate that hot flushes and the perimenopause are independent risk factors for depression. Thus, both hot flushes and perimenopause-related ovarian events may impart separate risks for developing depression at midlife. Indeed, Joffe and colleagues ${ }^{151}$ identified a significant association between hot flushes and depression in perimenopausal, but not postmenopausal, women. In our prospective study, hot flushes were not uniformly present in all women and, when present, did not necessarily precede the depression. Consistent with prior studies, eight of the nine women experiencing depression reported the onset of hot flushes at some point during the perimenopause, ${ }^{57,151}$ however, the timing of the relationship varied from several years before, to several years after, the onset of depression. Only four (44\%) of the women who developed a depression during the perimenopause reported the onset of hot flushes closely preceding the development of their depression. Fourth, a recent, clinic-based study of women with perimenopausal depression found that the presence of hot flushes distinguished neither the pattern of presenting symptoms (including the severity of sleep disturbance) nor the clinical characteristics (i.e., past psychiatric history, plasma FSH levels, severity of depression) in these women. ${ }^{67}$ Thus, hot flushes appear to be neither a necessary nor sufficient accompaniment of depression during the perimenopause, and perimenopausal depression cannot be dismissed as epiphenomenal to hot flushes. Finally, the effects of estrogen therapy on hot flushes and depression are dissociable; as mentioned above, there are women with perimenopausal depression without hot flushes whose depression responds to estrogen treatment. ${ }^{73}$ Further, as shown by Soares and colleagues, ${ }^{74}$ in women successfully treated for depression and hot flushes, estradiol withdrawal results in a return of hot flushes, but not necessarily depression. Thus, while hot flushes, sleep disturbance, and depression frequently cluster together in women during the menopause transition, a linear, causal relationship in which hot flush-induced dysomnia leads to perimenopausal depression remains to be confirmed.

\section{Life Events, Social Support, and Aging}

Some, but not all, studies have suggested that both midlife and the perimenopause are characterized by stressful life events and that perimenopausal depression may occur secondary to an increased number of stressful events, including personal losses. ${ }^{166}$ These stressors include the following: (1) alterations in family roles, (2) changing social support networks, (3) interpersonal losses, and (4) the physical effects of aging. Nevertheless, a causal role for such environmental factors has not been demonstrated. Midlife and, in particular, the perimenopause are not universally characterized by stressful life changes such as children leaving the home, one's becoming a grandparent, loss of employment, divorce or widowhood, or the onset of medical illness. ${ }^{167}$ Thus, it would be incorrect to assume that perimenopausal depression is a natural accompaniment of the stress of either midlife or the perimenopause.

Stressful events have been reported in association with depressive symptoms at midlife, ${ }^{42,51}$, 168,171 as well as in women with major and minor depression during the perimenopause. ${ }^{62}$,

${ }^{172}$ In the study by Schmidt and colleagues, ${ }^{172}$ however, women with perimenopausal 
depression did not report a greater number of exit events (i.e., personal losses) than asymptomatic perimenopausal women. Indeed, exit events, if they do occur, are not necessarily associated with negative mood symptoms in women at midlife. ${ }^{173}$ Thus, although stressful events are an accompaniment of both midlife and perimenopausal depression, there is no evidence to support the claim that depression at this time in a woman's life is caused by the "empty nest" syndrome.

Several factors such as genetic predisposition, ${ }^{174,175}$ self-efficacy, ${ }^{176}$ overall health, and social support ${ }^{177}$ may differentially modify the negative impact of life events and may determine whether negative events trigger the onset of depression. It is therefore possible that these variables may mediate the effects of negative life events on mood, resulting in depression among susceptible perimenopausal women. (It is important to note, however, that a woman's depressed state at the time of interview may color her perception of both the quantity and impact of negative events in her recent past.)

Models describing the menopause as a life crisis misrepresent both the negative impact of this developmental state and the universality of such an impact. ${ }^{42}$ The determinants of an individual's response to stressors, whether associated with the midlife or other developmental stages, are likely multifactorial and complex. It remains unclear which factors determine personal responses to crisis - whether they are positive, resulting in goal achievement, mastery, and a feeling of satisfaction with one's self and one's contributions, ${ }^{167}$ or negative, resulting in symptoms of emotional distress, low self-esteem, and depression. ${ }^{178}$

\section{Summary}

Perimenopausal depression is not simply the effect of abnormalities in ovarian steroid production and is not merely secondary to severe hot flushes or personal losses. Nonetheless, data suggest that each of these factors may play a role in perimenopausal depression and could potentially cause depression in certain women. Many of these same factors are also present, however, in the majority of perimenopausal women who do not develop depression. Thus, the mediating or protective factors involved in the development of depression remain to be determined.

\section{CLOSING REMARKS}

The relationship between the onset of depressive illness and reproductive aging has been a source of controversy. The epidemiologic and clinic-based studies that have distinguished between the perimenopause (a time of considerable variability in ovarian hormone secretion) and the postmenopause (a time when hormonal changes have long since stabilized) suggest that in some middle-aged women, the perimenopause is associated with an increased vulnerability to depression. Additional support for this suggestion is provided by double-blind, randomized, controlled trials documenting the therapeutic efficacy of estradiol in perimenopausal depressed women but not in postmenopausal depressed women. Our future efforts should abandon the all-or-none controversy and should be directed toward understanding the determinants and consequences of the variability that we see in the following: the response to change in reproductive endocrine function; the response, whether therapeutic or adverse, to hormonal therapy; the impact and duration of hypogonadism; and the behavioral effects of the large array of hormone receptor agonists and modulators.

\section{References}

1. Bevan Lewis, W. A text-book of mental diseases: with special reference to the pathological aspects of insanity. London: Griffin; 1899.

2. Conklin WJ. Some neuroses of the menopause. Trans Am Assoc Obstet Gynecol 1889;2:301-11. 
3. Maudsley, H. The physiology and pathology of the mind. New York: Appleton; 1867.

4. Kraepelin, E. Psychiatrie: ein Lehrbuch fur Studierende und Ärrzte. Leipzig: Barth; 1909.

5. Bleuler, E. Textbook of psychiatry. New York: Macmillan; 1924.

6. Stenstedt A. Involutional melancholia: an etiologic clinical and social study of endogenous depression in later life, with special reference to genetic factors. Acta Psychiatr Neurol Scand 1959;127:1-71.

7. American Psychiatric Association. Diagnostic and statistical manual of mental disorders. 1. Washington, DC: APA; 1952.

8. Werner AA, Johns GA, Hoctor EF, Ault CC, Kohler LW, Weis MW. Involutional melancholia: probable etiology and treatment. JAMA 1934;103:13-6.

9. Rosenthal S. The involutional depressive syndrome. Am J Psychiatry 1968;124:21-35. [PubMed: 4872232]

10. Weissman MM. The myth of involutional melancholia. JAMA 1979;242:742-4. [PubMed: 459064]

11. Winokur G. Depression in the menopause. Am J Psychiatry 1973;130:92-3. [PubMed: 4682753]

12. Myers JK, Weissman MM, Tischler GL, et al. Six-month prevalence of psychiatric disorders in three communities. Arch Gen Psychiatry 1984;41:959-67. [PubMed: 6332591]

13. Brown RP, Sweeney J, Loutsch E, Kocsis J, Frances A. Involutional melancholia revisited. Am J Psychiatry 1984;141:24-8. [PubMed: 6691457]

14. Soules MR, Sherman S, Parrott E, et al. Executive summary: Stages of Reproductive Aging Workshop (STRAW). Fertil Steril 2001;76:874-8. [PubMed: 11704104]

15. Santoro N, Brown JR, Adel T, Skurnick JH. Characterization of reproductive hormonal dynamics in the perimenopause. J Clin Endocrinol Metab 1996;81:1495-1501. [PubMed: 8636357]

16. Treloar AE. Menstrual cyclicity and the pre-menopause. Maturitas 1981;3:249-64. [PubMed: 7334935]

17. Richardson SJ. The biological basis of the menopause. Baillieres Clin Endocrinol Metab 1993;7:116. [PubMed: 8435048]

18. Miro F, Parker SW, Aspinall LJ, Coley J, Perry PW, Ellis JE. Relationship between folliclestimulating hormone levels at the beginning of the human menstrual cycle, length of the follicular phase and excreted estrogens: the FREEDOM study. J Clin Endocrinol Metab 2004;89:3270-5. [PubMed: 15240602]

19. Klein NA, Harper AJ, Houmard BS, Sluss PM, Soules MR. Is the short follicular phase in older women secondary to advanced or accelerated dominant follicle development? J Clin Endocrinol Metab 2002;87:5746-50. [PubMed: 12466381]

20. Hall JE. Neuroendocrine changes with reproductive aging in women. Semin Reprod Med 2007;25:344-51. [PubMed: 17710730]

21. Hall JE. Neuroendocrine physiology of the early and late menopause. Endocrinol Metab Clin North Am 2004;33:637-59. [PubMed: 15501638]

22. Welt CK, Jimenez Y, Sluss PM, Smith PC, Hall JE. Control of estradiol secretion in reproductive ageing. Hum Reprod 2006;21:2189-93. [PubMed: 16684841]

23. Burger HG, Dudley EC, Hopper JL, et al. The endocrinology of the menopausal transition: a crosssectional study of a population-based sample. J Clin Endocrinol Metab 1995;80:3537-45. [PubMed: 8530596]

24. Hale GE, Zhao X, Hughes CL, Burger HG, Robertson DM, Fraser IS. Endocrine features of menstrual cycles in middle and late reproductive age and the menopausal transition classified according to the staging of reproductive aging workshop (STRAW) staging system. J Clin Endocrinol Metab 2007;92:3060-7. [PubMed: 17550960]

25. Freeman EW, Sammel MD, Gracia CR, et al. Follicular phase hormone levels and menstrual bleeding status in the approach to menopause. Fertil Steril 2005;83:383-92. [PubMed: 15705379]

26. Couzinet B, Meduri G, Lecce MG, et al. The postmenopausal ovary is not a major androgen-producing gland. J Clin Endocrinol Metab 2001;86:5060-6. [PubMed: 11600585]

27. Davison SL, Donath S, Montalto JG, Davis SR. Androgen levels in adult females: changes with age, menopause, and oophorectomy. J Clin Endocrinol Metab 2005;90:3847-53. [PubMed: 15827095]

28. Fogle RH, Stanczyk FZ, Zhang X, Paulson RJ. Ovarian androgen production in postmenopausal women. J Clin Endocrinol Metab 2007;92:3040-3. [PubMed: 17519304] 
29. Chen J, Sowers MR, Moran FM, et al. Circulating bioactive androgens in midlife women. J Clin Endocrinol Metab 2006;91:4387-94. [PubMed: 16940455]

30. Kaufert PA, Gilbert P, Tate R. Defining menopausal status: the impact of longitudinal data. Maturitas 1987;9:217-26. [PubMed: 3431474]

31. Guthrie J, Dennerstein L, Burger H. How reliably does 12-month amenorrhea define final menstrual period? Data from a longitudinal study. Climacteric 2002;5:92. [PubMed: 11974565]

32. Harlow SD, Cain K, Crawford S, et al. Evaluation of four proposed bleeding criteria for the onset of late menopausal transition. J Clin Endocrinol Metab 2006;91:3432-8. [PubMed: 16772350]

33. Ferrell RJ, Simon JA, Pincus SM, et al. The length of perimenopausal menstrual cycles increases later and to a greater degree than previously reported. Fertil Steril 2006;86:619-24. [PubMed: 16889776]

34. Randolph JF Jr, Crawford S, Dennerstein L, et al. The value of follicle-stimulating hormone concentration and clinical findings as markers of the late menopausal transition. J Clin Endocrinol Metab 2006;91:3034-40. [PubMed: 16720656]

35. American Psychiatric Association. Diagnostic and statistical manual of mental disorders. 4. Washington, DC: APA; 1994.

36. Spitzer, RL.; Williams, JB.; Gibbon, M.; First, MB. Structured clinical interview for DSM-III-R Patient edition. New York: Biometrics Research Department, New York State Psychiatric Institute; 1990.

37. Spijker J, de Graaf R, Bijl RV, Beekman ATF, Ormel J, Nolen WA. Duration of major depressive episodes in the general population: results from the Netherlands Mental Health Survey and Incidence Study (NEMESIS). Br J Psychiatry 2002;181:208-13. [PubMed: 12204924]

38. Roberts RE, Vernon SW. The center for epidemiologic studies depression scale: its use in a community sample. Am J Psychiatry 1983;140:41-6. [PubMed: 6847983]

39. Gaynes, BN.; Gavin, N.; Meltzer-Brody, S., et al. Perinatal depression: prevalence, screening accuracy, and screening outcomes. Agency for Healthcare Research and Quality. 2005. http://www.ahrq.gov/downloads/pub/evidence/pdf/peridepr/peridep.pdf

40. Weissman MM, Leaf PJ, Tischler GL, et al. Affective disorders in five United States communities. Psychol Med 1988;18:141-53. [PubMed: 3363034]

41. Kessler RC, McGonagle KA, Swartz M, Blazer DG, Nelson CB. Sex and depression in the National Comorbidity Survey I: lifetime prevalence, chronicity and recurrence. J Affect Disord 1993;29:8596. [PubMed: 8300981]

42. McKinlay JB, McKinlay SM, Brambilla D. The relative contributions of endocrine changes and social circumstances to depression in mid-aged women. J Health Soc Behav 1987;28:345-63. [PubMed: 3429805]

43. Kaufert PA, Gilbert P, Tate R. The Manitoba project: a reexamination of the link between menopause and depression. Maturitas 1992;14:143-55. [PubMed: 1565022]

44. Avis NE, Brambilla D, McKinlay SM, Vass K. A longitudinal analysis of the association between menopause and depression: results from the Massachusetts Women's Health Study. Ann Epidemiol 1994;4:214-20. [PubMed: 8055122]

45. Matthews KA, Wing RR, Kuller LH, et al. Influences of natural menopause on psychological characteristics and symptoms of middle-aged healthy women. J Consult Clin Psychol 1990;58:34551. [PubMed: 2365898]

46. Holte A. Influences of natural menopause on health complaints: a prospective study of healthy Norwegian women. Maturitas 1992;14:127-41. [PubMed: 1565021]

47. Fugate Woods N, Mariella A, Sullivan Mitchell E. Patterns of depressed mood across the menopausal transition: approaches to studying patterns in longitudinal data. Acta Obstet Gynecol Scand 2002;81:623-32. [PubMed: 12190837]

48. Maartens LW, Leusink GL, Knottnerus JA, Smeets CG, Pop VJ. Climacteric complaints in the community. Fam Pract 2001;18:189-94. [PubMed: 11264270]

49. Den Tonkelaar I, Broekmans FJ, De Boer EJ, et al. The stages of reproductive aging workshop. Menopause 2002;9:463-4. [PubMed: 12439107]

50. Hardy R, Kuh D. Change in psychological and vasomotor symptom reporting during the menopause. Soc Sci Med 2002;55:1975-88. [PubMed: 12406465] 
51. Dennerstein L, Lehert P, Burger H, Dudley E. Mood and the menopausal transition. J Nerv Ment Dis 1999;187:685-91. [PubMed: 10579597]

52. Hunter M. The South-East England longitudinal study of the climacteric and postmenopause. Maturitas 1992;14:117-26. [PubMed: 1565020]

53. O'Connor VM, Del Mar CB, Sheehan M, Siskind V, Fox-Young S, Cragg C. Do psychosocial factors contribute more to symptom reporting by middle-aged women than hormonal status? Maturitas 1995;20:63-9.

54. Bromberger JT, Meyer PM, Kravitz HM, et al. Psychologic distress and natural menopause: a multiethnic community study. Am J Public Health 2001;91:1435-42. [PubMed: 11527777]

55. Maartens LWF, Knottnerus JA, Pop VJ. Menopausal transition and increased depressive symptomatology: a community based prospective study. Maturitas 2002;42:195-200. [PubMed: 12161043]

56. Bromberger JT, Assmann SF, Avis NE, Schocken M, Kravitz HM, Cordal A. Persistent mood symptoms in a multiethnic community cohort of pre- and perimenopausal women. Am J Epidemiol 2003;158:347-56. [PubMed: 12915500]

57. Freeman EW, Sammel MD, Liu L, Gracia CR, Nelson DB, Hollander L. Hormones and menopausal status as predictors of depression in women in transition to menopause. Arch Gen Psychiatry 2004;61:62-70. [PubMed: 14706945]

58. Stewart DE, Boydell K, Derzko C, Marshall V. Psychologic distress during the menopausal years in women attending a menopause clinic. Int J Psychiatry Med 1992;22:213-20. [PubMed: 1487384]

59. Dennerstein L, Smith AMA, Morse C, et al. Menopausal symptoms in Australian women. Med J Aust 1993;159:232-6. [PubMed: 8412889]

60. Hay AG, Bancroft J, Johnstone EC. Affective symptoms in women attending a menopause clinic. Br J Psychiatry 1994;164:513-6. [PubMed: 8038941]

61. Spitzer RL, Williams JBW, Kroenke K, et al. Utility of a new procedure for diagnosing mental disorders in primary care: the PRIME-MD 1000 study. JAMA 1994;272:1749-56. [PubMed: 7966923]

62. Cohen LS, Soares CN, Vitonis AF, Otto MW, Harlow BL. Risk for new onset of depression during the menopausal transition. The Harvard study of moods and cycles. Arch Gen Psychiatry 2006;63:385-90. [PubMed: 16585467]

63. Freeman EW, Sammel MD, Lin H, Nelson DB. Associations of hormones and menopausal status with depressed mood in women with no history of depression. Arch Gen Psychiatry 2006;63:37582. [PubMed: 16585466]

64. Bromberger JT, Matthews KA, Schott LL, et al. Depressive symptoms during the menopausal transition: the study of women's health across the nation (SWAN). J Affect Disord 2007;103:26772. [PubMed: 17331589]

65. Bromberger, JT.; Kravitz, HM.; Matthews, KA.; Youk, A.; Brown, C.; Feng, W. Predictors of first episodes of clinical depression in midlife women. Abstract presented at the 160th annual meeting of the American Psychiatric Association; San Diego, CA. May 2007;

66. Schmidt PJ, Haq NA, Rubinow DR. A longitudinal evaluation of the relationship between reproductive status and mood in perimenopausal women. Am J Psychiatry 2004;161:2238-44. [PubMed: 15569895]

67. Steinberg EM, Rubinow DR, Bartko JJ, et al. A cross sectional evaluation of perimenopausal depression. J Clin Psychiatry 2008;69:973-80. [PubMed: 18505304]

68. Gold EB, Colvin A, Avis N, et al. Longitudinal analysis of the association between vasomotor symptoms and race/ethnicity across the menopausal transition: study of women's health across the nation. Am J Public Health 2006;96:1226-35. [PubMed: 16735636]

69. Juang KD, Wang SJ, Lu SR, Lee SJ, Fuh JL. Hot flashes are associated with psychological symptoms of anxiety and depression in peri- and post-but not premenopausal women. Maturitas 2005;52:11926. [PubMed: 16186074]

70. Freeman EW, Sammel MD, Grisso JA, Battistini M, Garcia-Espagna B, Hollander L. Hot flashes in the late reproductive years: risk factors for African American and Caucasian women. J Womens Health Gend Based Med 2001;10:67-76. [PubMed: 11224946] 
71. Freeman EW, Sammel MD, Lin H, Gracia CR, Kapoor S, Ferdousi T. The role of anxiety and hormonal changes in menopausal hot flashes. Menopause 2005;12:258-66. [PubMed: 15879914]

72. Appleby, L.; Montgomery, J.; Studd, J. Oestrogens and affective disorders. In: Studd, J., editor. Progress in obstetrics and gynaecology. Edinburgh: Churchill Livingstone; 1981. p. 289-302.

73. Schmidt PJ, Nieman L, Danaceau MA, et al. Estrogen replacement in perimenopause-related depression: a preliminary report. Am J Obstet Gynecol 2000;183:414-20. [PubMed: 10942479]

74. Soares CD, Almeida OP, Joffe H, Cohen LS. Efficacy of estradiol for the treatment of depressive disorders in perimenopausal women: a double-blind, randomized, placebo-controlled trial. Arch Gen Psychiatry 2001;58:529-34. [PubMed: 11386980]

75. Morrison MF, Kallan MJ, Ten Have T, Katz I, Tweedy K, Battistini M. Lack of efficacy of estradiol for depression in postmenopausal women: a randomized, controlled trial. Biol Psychiatry 2004;55:406-12. [PubMed: 14960294]

76. Yaffe K, Sawaya G, Lieberburg I, Grady D. Estrogen therapy in postmenopausal women: effects on cognitive function and dementia. JAMA 1998;279:688-95. [PubMed: 9496988]

77. LeBlanc ES, Janowsky J, Chan BKS, Nelson HD. Hormone replacement therapy and cognition: systematic review and meta-analysis. JAMA 2001;285:1489-99. [PubMed: 11255426]

78. Hogervorst E, Yaffe K, Richards M, Huppert F. Hormone replacement therapy for cognitive function in postmenopausal women. Cochrane Database Syst Rev 2002;(3):CD003122. [PubMed: 12137675]

79. Gibbs RB. Long-term treatment with estrogen and progesterone enhances acquisition of a spatial memory task by ovariectomized aged rats. Neurobiol Aging 2000;21:107-16. [PubMed: 10794855]

80. Zandi PP, Carlson MC, Plassman BL, et al. Hormone replacement therapy and incidence of Alzheimer disease in older women: the Cache County study. JAMA 2002;288:2123-9. [PubMed: 12413371]

81. Resnick SM, Henderson VW. Hormone therapy and risk of Alzheimer disease: a critical time. JAMA 2002;288:2170-2. [PubMed: 12413378]

82. Mikkola TS, Clarkson TB. Estrogen replacement therapy, atherosclerosis, and vascular function. Cardiovasc Res 2002;53:605-19. [PubMed: 11861031]

83. Manson JE, Allison MA, Rossouw JE, et al. Estrogen therapy and coronary-artery calcification. N Engl J Med 2007;356:2591-602. [PubMed: 17582069]

84. Manson JE, Bassuk SS. Invited commentary: hormone therapy and risk of coronary heart diseasewhy renew the focus on the early years of menopause? Am J Epidemiol 2007;166:511-7. [PubMed: 17646204]

85. Hodis HN, Mack WJ. Postmenopausal hormone therapy in clinical perspective. Menopause 2007;14:944-57. [PubMed: 17353803]

86. Rossouw JE, Prentice RL, Manson JE, et al. Postmenopausal hormone therapy and risk of cardiovascular disease by age and years since menopause. JAMA 2007;297:1465-77. [PubMed: 17405972]

87. Rossouw JE, Anderson GL, Prentice RL, et al. Writing Group for the Women's Health Initiative Investigators. Risks and benefits of estrogen plus progestin in healthy postmenopausal women: principal results from the Women's Health Initiative randomized controlled trial. JAMA 2002;288:321-33. [PubMed: 12117397]

88. Shumaker SA, Legault C, Rapp SR, et al. Estrogen plus progestin and the incidence of dementia and mild cognitive impairment in postmenopausal women: the Women's Health Initiative Memory Study: a randomized controlled trial. JAMA 2003;289:2651-62. [PubMed: 12771112]

89. Grodstein F, Clarkson TB, Manson JE. Understanding the divergent data on postmenopausal hormone therapy. N Engl J Med 2003;348:645-50. [PubMed: 12584376]

90. Herrington DM, Howard TD, Hawkins GA, et al. Estrogen-receptor polymorphisms and effects of estrogen replacement on high-density lipoprotein cholesterol in women with coronary disease. N Engl J Med 2002;346:967-74. [PubMed: 11919305]

91. Yaffe K, Lui LY, Grady D, Stone K, Morin P. Estrogen receptor 1 polymorphism and risk of cognitive impairment in older women. Biol Psychiatry 2002;51:677-82. [PubMed: 11955468]

92. Woolley CS, Schwartzkroin PA. Hormonal effects on the brain. Epilepsia 1998;39:S2-S8. [PubMed: 9915614] 
93. McEwen BS. Basic neurobiology of ovarian steroids: clinical implications. Dial Clin Neurosci 2002;4:163-75.

94. Rachman IM, Unnerstall JR, Pfaff DW, Cohen RS. Estrogen alters behavior and forebrain c-fos expression in ovariectomized rats subjected to the forced swim test. Proc Natl Acad Sci U S A 1998;95:13941-6. [PubMed: 9811905]

95. Rubinow DR, Schmidt PJ, Roca CA. Estrogen-serotonin interactions: implications for affective regulation. Biol Psychiatry 1998;44:839-50. [PubMed: 9807639]

96. Pecins-Thompson M, Brown NA, Bethea CL. Regulation of serotonin re-uptake transporter mRNA expression by ovarian steroids in rhesus macaques. Brain Res Mol Brain Res 1998;53:120-9. [PubMed: 9473622]

97. McQueen JK, Wilson H, Fink G. Estradiol-17ß increases serotonin transporter (SERT) mRNA levels and the density of SERT-binding sites in female rat brain. Brain Res Mol Brain Res 1997;45:13-23. [PubMed: 9105666]

98. Lu NZ, Eshleman AJ, Janowsky J, Bethea CL. Ovarian steroid regulation of serotonin reuptake transporter (SERT) binding, distribution, and function in female macaques. Mol Psychiatry 2003;8:353-60. [PubMed: 12660809]

99. Clarke WP, Maayani S. Estrogen effects on 5-HT $1 \mathrm{~A}$ receptors in hippocampal membranes from ovariectomized rats: functional and binding studies. Brain Res 1990;518:287-91. [PubMed: 2143962]

100. Thomas ML, Bland DA, Clarke CH, Cunningham KA. Estrogen regulation of serotonin (5-HT) transporter and 5-HT $1 A$ receptor mRNA in female rat brain. Abstr Soc Neurosci 1997;23:1501.

101. Sumner BEH, Fink G. Estrogen increases the density of 5-hydroxytryptamine $2 \mathrm{~A}$ receptors in cerebral cortex and nucleus accumbens in the female rat. J Steroid Biochem Mol Biol 1995;54:15-20. [PubMed: 7632610]

102. Maswood S, Truitt W, Hotema M, Caldarola-Pastuszka M, Uphouse L. Estrous cycle modulation of extracellular serotonin in mediobasal hypothalamus: role of the serotonin transporter and terminal autoreceptors. Brain Res 1999;831:146-54. [PubMed: 10411994]

103. Nestler EJ, Terwilliger RZ, Duman RS. Chronic antidepressant administration alters the subcellular distribution of cyclic AMP-dependent protein kinase in rat frontal cortex. J Neurochem 1989;53:1644-7. [PubMed: 2795022]

104. Duman RS, Heninger GR, Nestler EJ. A molecular and cellular theory of depression. Arch Gen Psychiatry 1997;54:597-606. [PubMed: 9236543]

105. Nibuya M, Nestler EJ, Duman RS. Chronic antidepressant administration increases the expression of cAMP response element-binding protein (CREB) in rat hippocampus. J Neurosci 1996;16:236572. [PubMed: 8601816]

106. Rantamaki T, Hendolin P, Kankaanpaa A, et al. Pharmacologically diverse antidepressants rapidly activate brain-derived neurotrophic factor receptor TrkB and induce phospholipase-Cgamma signaling pathways in mouse brain. Neuropsychopharmacology 2007;32:2152-62. [PubMed: 17314919]

107. Russo-Neustadt A, Ha T, Ramirez R, Kesslak JP. Physical activity-antidepressant treatment combination: impact on brain-derived neurotrophic factor and behavior in an animal model. Behav Brain Res 2001;120:87-95. [PubMed: 11173088]

108. Martinez-Turrillas R, Del Rio J, Frechilla D. Sequential changes in BDNF mRNA expression and synaptic levels of AMPA receptor subunits in rat hippocampus after chronic antidepressant treatment. Neuropharmacology 2005;49:1178-88. [PubMed: 16143352]

109. Kozisek ME, Middlemas D, Bylund DB. The differential regulation of BDNF and TrkB levels in juvenile rats after four days of escitalopram and desipramine treatment. Neuropharmacology 2008;54:251-7. [PubMed: 18048068]

110. Sohrabji F, Greene LA, Miranda RC, Toran-Allerand CD. Reciprocal regulation of estrogen and NGF receptors by their ligands in PC12 cells. J Neurobiol 1994;25:974-88. [PubMed: 7525871]

111. Jezierski MK, Sohrabji F. Region- and peptide-specific regulation of the neurotrophins by estrogen. Mol Brain Res 2000;85:77-84. [PubMed: 11146109]

112. Jezierski MK, Sohrabji F. Estrogen enhances retrograde transport of brain-derived neurotrophic factor in the rodent forebrain. Endocrinology 2003;144:5022-9. [PubMed: 12960034] 
113. Zhou Y, Watters JJ, Dorsa DM. Estrogen rapidly induces the phosphorylation of the cAMP response element binding protein in rat brain. Endocrinology 1996;137:2163-6. [PubMed: 8612562]

114. Murphy DD, Cole NB, Segal M. Brain-derived neurotrophic factor mediates estradiol-induced dendritic spine formation in hippocampal neurons. Proc Natl Acad Sci U S A 1998;95:11412-7. [PubMed: 9736750]

115. Antonijevic IA, Stalla GK, Steiger A. Modulation of the sleep electroencephalogram by estrogen replacement in postmenopausal women. Am J Obstet Gynecol 2000;182:277-82. [PubMed: 10694324]

116. Wilkie MJV, Smith D, Reid IC, et al. A splice site polymorphism in the G-protein $\beta$ subunit influences antidepressant efficacy in depression. Pharmacogenet Genomics 2007;17:207-15. [PubMed: 17460549]

117. Prossnitz ER, Sklar LA, Oprea TI, Arterburn JB. GPR30: a novel therapeutic target in estrogenrelated disease. Trends Pharmacol Sci 2008;29:116-23. [PubMed: 18262661]

118. Levin ER. Integration of the extranuclear and nuclear actions of estrogen. Mol Endocrinol 2005;19:1951-9. [PubMed: 15705661]

119. Kelly MJ, Wagner EJ. Estrogen modulation of G-protein-coupled receptors. Trends Endocrinol Metab 1999;10:369-74. [PubMed: 10511696]

120. Steingold KA, Laufer L, Chetkowski RJ, et al. Treatment of hot flashes with transdermal estradiol administration. J Clin Endocrinol Metab 1985;61:627-32. [PubMed: 3928674]

121. Brincat M, Studd JWW, O'Dowd T, et al. Subcutaneous hormone implants for the control of climacteric symptoms: a prospective study. Lancet 1984;323:16-8. [PubMed: 6140343]

122. Ditkoff EC, Crary WG, Cristo M, Lobo RA. Estrogen improves psychological function in asymptomatic postmenopausal women. Obstet Gynecol 1991;78:991-5. [PubMed: 1658700]

123. Sherwin BB, Gelfand MM. Differential symptom response to parenteral estrogen and/or androgen administration in the surgical menopause. Am J Obstet Gynecol 1985;151:153-60. [PubMed: 3881960]

124. Brambilla F, Maggioni M, Ferrari E, Scarone S, Catalano M. Tonic and dynamic gonadotropin secretion in depressive and normothymic phases of affective disorders. Psychiatry Res 1990;32:229-39. [PubMed: 2117763]

125. Amsterdam JD, Winokur A, Lucki I, Snyder P. Neuroendocrine regulation in depressed postmenopausal women and healthy subjects. Acta Psychiatr Scand 1983;67:43-9. [PubMed: 6405581]

126. Altman N, Sachar EJ, Gruen PH, Halpern FS, Eto S. Reduced plasma LH concentration in postmenopausal depressed women. Psychosom Med 1975;37:274-6. [PubMed: 1178796]

127. Guicheney P, Léger D, Barrat J, et al. Platelet serotonin content and plasma tryptophan in peri- and postmenopausal women: variations with plasma oestrogen levels and depressive symptoms. Eur J Clin Invest 1988;18:297-304. [PubMed: 3138133]

128. Ballinger S. Stress as a factor in lowered estrogen-levels in the early postmenopause. Ann N Y Acad Sci 1990;592:95-113. [PubMed: 2197957]

129. Huerta R, Mena A, Malacara JM, Diaz de Leon J. Symptoms at perimenopausal period: its association with attitudes toward sexuality, life-style, family function, and FSH levels. Psychoneuroendocrinology 1995;20:135-48. [PubMed: 7899534]

130. Saletu B, Brandstatter N, Metka M, et al. Hormonal, syndromal and EEG mapping studies in menopausal syndrome patients with and without depression as compared with controls. Maturitas 1996;23:91-105. [PubMed: 8861091]

131. Barrett-Connor E, von Muhlen D, Laughlin GA, Kripke A. Endogenous levels of dehydroepiandrosterone sulfate, but not other sex hormones, are associated with depressed mood in older women: the Rancho Bernardo study. J Am Geriatr Soc 1999;47:685-91. [PubMed: 10366167]

132. Cawood EH, Bancroft J. Steroid hormones, the menopause, sexuality and well-being of women. Psychol Med 1996;26:925-36. [PubMed: 8878326]

133. Schmidt PJ, Murphy JH, Haq N, Danaceau MA, Simpson St.Clair L. Basal plasma hormone levels in depressed perimenopausal women. Psychoneuroendocrinology 2002;27:907-20. [PubMed: 12383452] 
134. Matthews KA. Myths and realities of the menopause. Psychosom Med 1992;54:1-9. [PubMed: 1553395]

135. Majewska MD, Demirgören S, Spivak CE, London ED. The neurosteroid dehydroepiandrosterone sulfate is an allosteric antagonist of the $\mathrm{GABA}_{A}$ receptor. Brain Res 1990;526:143-6. [PubMed: 1964106]

136. Baulieu E-E, Robel P. Dehydroepiandrosterone (DHEA) and dehydroepiandrosterone sulfate (DHEAS) as neuroactive neurosteroids. Proc Natl Acad Sci U S A 1998;95:4089-91. [PubMed: 9539693]

137. Zwain IH, Yen SSC. Dehydroepiandrosterone: biosynthesis and metabolism in the brain. Endocrinology 1999;140:880-7. [PubMed: 9927319]

138. Morales AJ, Nolan JJ, Nelson JC, Yen SSC. Effects of replacement dose of dehydroepiandrosterone in men and women of advancing age. J Clin Endocrinol Metab 1994;78:1360-7. [PubMed: 7515387]

139. Wolkowitz OM, Reus VI, Keebler A, et al. Double-blind treatment of major depression with dehydroepiandrosterone. Am J Psychiatry 1999;156:646-9. [PubMed: 10200751]

140. Bloch M, Schmidt PJ, Danaceau MA, Adams LF, Rubinow DR. Dehydroepiandrosterone treatment of mid-life dysthymia. Biol Psychiatry 1999;45:1533-41. [PubMed: 10376113]

141. Schmidt PJ, Daly RC, Bloch M, et al. Dehydroepiandrosterone monotherapy in midlife-onset major and minor depression. Arch Gen Psychiatry 2005;62:154-62. [PubMed: 15699292]

142. Wolf OT, Neumann O, Hellhammer DH, et al. Effects of a two-week physiological dehydroepiandrosterone substitution on cognitive performance and well-being in healthy elderly women and men. J Clin Endocrinol Metab 1997;82:2363-7. [PubMed: 9215320]

143. Laughlin GA, Barrett-Connor E. Sexual dimorphism in the influence of advanced aging on adrenal hormone levels: the Rancho Bernardo study. J Clin Endocrinol Metab 2000;85:3561-8. [PubMed: 11061502]

144. Ferrari, E.; Locatelli, M.; Arcaini, A., et al. Chronobiological study of some neuroendocrine features of major depression in elderly people. Abstract presented at the 79th annual meeting of the Endocrine Society; Minneapolis, MN. June 1997;

145. Daly RC, Danaceau MA, Rubinow DR, Schmidt PJ. Concordant restoration of ovarian function and mood in perimenopausal depression. Am J Psychiatry 2003;160:1842-6. [PubMed: 14514500]

146. Zweifel JE, O'Brien WH. A meta-analysis of the effect of hormone replacement therapy upon depressed mood. Psychoneuroendocrinology 1997;22:189-212. [PubMed: 9203229]

147. Montgomery JC, Brincat M, Tapp A, et al. Effect of oestrogen and testosterone implants on psychological disorders in the climacteric. Lancet 1987;329:297-9. [PubMed: 2880114]

148. Saletu B, Brandstatter N, Metka M, et al. Double-blind, placebo-controlled, hormonal, syndromal and EEG mapping studies with transdermal oestradiol therapy in menopausal depression. Psychopharmacology 1995;122:321-9. [PubMed: 8657828]

149. Spitzer RL, Kroenke K, Linzer M, et al. Health-related quality of life in primary care patients with mental disorders: results from the PRIME-MD 1000 study. JAMA 1995;274:1511-7. [PubMed: 7474219]

150. Jaszmann L, van Lith ND, Zaat JCA. The perimenopausal symptoms: the statistical analysis of a survey Part A. Med Gynaecol Sociol 1969;4:268-77.

151. Joffe H, Hall JE, Soares CN, et al. Vasomotor symptoms are associated with depression in perimenopausal women seeking primary care. Menopause 2002;9:392-8. [PubMed: 12439097]

152. Dennerstein L, Dudley EC, Hopper JL, Guthrie JR, Burger HG. A prospective population-based study of menopausal symptoms. Obstet Gynecol 2000;96:351-8. [PubMed: 10960625]

153. Schiff I, Regestein Q, Tulchinsky D, Ryan KJ. Effects of estrogens on sleep and psychological state of hypogonadal women. JAMA 1979;242:2405-7. [PubMed: 226735]

154. Owens JF, Matthews KA. Sleep disturbance in healthy middle-aged women. Maturitas 1998;30:4150. [PubMed: 9819782]

155. Polo-Kantola P, Saaresranta T, Polo O. Aetiology and treatment of sleep disturbances during perimenopause and postmenopause. CNS Drugs 2001;15:445-52. [PubMed: 11524023] 
156. Polo-Kantola P, Erkkola R, Helenius H, Irjala K, Polo O. When does estrogen replacement therapy improve sleep quality? Am J Obstet Gynecol 1998;178:1002-9. [PubMed: 9609575]

157. Kravitz HM, Ganz PA, Bromberger J, Powell LH, Sutton-Tyrrell K, Meyer PM. Sleep difficulty in women at midlife: a community survey of sleep and the menopausal transition. Menopause 2003;10:19-28. [PubMed: 12544673]

158. Ohayon MM. Severe hot flashes are associated with chronic insomnia. Arch Intern Med 2006;166:1262-8. [PubMed: 16801508]

159. Freedman RR, Roehrs TA. Effects of REM sleep and ambient temperature on hot flash-induced sleep disturbance. Menopause 2006;13:576-83. [PubMed: 16837879]

160. Freedman RR, Roehrs TA. Lack of sleep disturbance from menopausal hot flashes. Fertil Steril 2004;82:138-44. [PubMed: 15237002]

161. Neckelmann D, Mykletun A, Dahl AA. Chronic insomnia as a risk factor for developing anxiety and depression. Sleep 2007;30:873-80. [PubMed: 17682658]

162. Morphy H, Dunn KM, Lewis M, Boardman HF, Croft PR. Epidemiology of insomnia: a longitudinal study in a UK population. Sleep 2007;30:274-80. [PubMed: 17425223]

163. Kahn-Greene ET, Killgore DB, Kamimori GH, Balkin TJ, Killgore WDS. The effects of sleep deprivation on symptoms of psychopathology in healthy adults. Sleep Med 2007;8:215-21. [PubMed: 17368979]

164. Freedman RR, Roehrs TA. Sleep disturbance in menopause. Menopause 2007;14:826-9. [PubMed: 17486023]

165. Avis NE, Stellato R, Crawford S, et al. Is there a menopausal syndrome? Menopausal status and symptoms across racial/ethnic groups. Soc Sci Med 2001;52:345-56. [PubMed: 11330770]

166. Cooke DJ, Greene JG. Types of life events in relation to symptoms at the climacterium. J Psychosom Res 1981;25:5-11. [PubMed: 7277267]

167. Dennerstein L, Lehert P, Dudley E, Guthrie J. Factors contributing to positive mood during the menopausal transition. J Nerv Ment Dis 2001;189:84-9. [PubMed: 11225691]

168. Greene JG, Cooke DJ. Life stress and symptoms at the climacterium. Br J Psychiatry 1980;136:48691. [PubMed: 7388253]

169. Ballinger S, Cobbin D, Krivanek J, Saunders D. Life stresses and depression in the menopause. Maturitas 1979;1:191-9. [PubMed: 502876]

170. Mitchell ES, Woods NF. Symptom experiences of midlife women: observations from the Seattle midlife women's health study. Maturitas 1996;25:1-10. [PubMed: 8887303]

171. Woods NF, Mitchell ES. Pathways to depressed mood for midlife women: observations from the Seattle midlife women's health study. Res Nurs Health 1997;20:119-29. [PubMed: 9100742]

172. Schmidt PJ, Murphy JH, Haq NA, Rubinow DR, Danaceau M. Stressful life events, personal losses, and perimenopause-related depression. Arch Womens Ment Health 2004;7:19-26. [PubMed: 14963729]

173. Dennerstein L, Dudley E, Guthrie J. Empty nest or revolving door? A prospective study of women's quality of life in midlife during the phase of children leaving and re-entering the home. Psychol Med 2002;32:545-50. [PubMed: 11989999]

174. Kendler KS, Kessler RC, Walters EE, et al. Stressful life events, genetic liability, and onset of an episode of major depression in women. Am J Psychiatry 1995;152:833-42. [PubMed: 7755111]

175. Caspi A, Sugden K, Moffitt TE, et al. Influence of life stress on depression: moderation by a polymorphism in the 5-HTT gene. Science 2003;301:291-3. [PubMed: 12869733]

176. Maciejewski PK, Prigerson HG, Mazure CM. Sex differences in event-related risk for major depression. Psychol Med 2001;31:593-604. [PubMed: 11352362]

177. Seeman TE, Crimmins E. Social environment effects on health and aging: integrating epidemiologic and demographic approaches and perspectives. Ann N Y Acad Sci 2001;954:88-117. [PubMed: 11797869]

178. Erikson EH. Eight ages of man. Int J Psychiatry 1966;2:281-307. [PubMed: 5934808] 